\title{
A Importância da Ludicidade na Interface de um Jogo Educativo para Estimulação do Controle Inibitório
}

\author{
Ariane Nunes Rodrigues, Arianne Sarmento Torcate \\ Universidade de Pernambuco (UPE) \\ ariane.rodrigues@upe.br, ast@ecomp.poli.br
}

\begin{abstract}
This article associate fun as responsible for learning in serious games promoted by the interface. The research reinforces the need for the quality of educational interfaces through the use of visual representations and adequate feedbacks. In this context, there are playful aspects of the game's Candy Night interface, focused on stimulating inhibitory control. The results of the evaluation of the game interface, from the perspective of real users, reveal the importance of ensuring fun in order to achieve learning objectives.

Resumo. Este artigo relaciona a ludicidade como responsável para a aprendizagem em jogos educativos promovida pela interface. A pesquisa reforça a necessidade da qualidade das interfaces educativas pelo uso de representações visuais e feedbacks adequados. Neste contexto, destaca-se aspectos lúdicos da interface do jogo Candy Night focado para estimular o controle inibitório. Os resultados da avaliação da interface do jogo, sob a perspectiva de usuários reais, revelam a importância de garantir a diversão para atingir os objetivos de aprendizagem.
\end{abstract}

\section{Introdução}

Pesquisas sobre o desenvolvimento de jogos educativos (também definidos como sérios) sempre reforçam a importância de garantir a qualidade para a aprendizagem. Uma característica que define os jogos como sérios, citado em Silva e Gomes (2015, p.89), está em utilizar o "entretenimento, do prazer e da diversão para conseguir os objetivos primordiais". Para os autores, este tipo de jogo é uma categoria de software educativo que, mesmo sendo divertido, este não é o seu propósito principal.

Esta pesquisa destaca que a interface é um dos elementos fundamentais que definem a qualidade do jogo. Destacar a qualidade da interface significa estabelecer representações adequadas para que os objetivos sejam atingidos. A interação pela interface acontece por meio do contato físico e conceitual (Barbosa e Silva, 2010). Por exemplo, quando o usuário pressiona a tela do celular para movimentar um personagem estamos nos referindo ao contato físico. O contato conceitual ocorre por influências das interpretações do usuário após o contato físico. Ou seja, este contato acontece quando o usuário percebe e interpreta, pela interface, que o seu personagem está se movimentando para a direção correta.

Não há um consenso na literatura de como relacionar atributos de qualidade ao processo de concepção das interfaces. Para Crawford (1982), quatro elementos são fundamentais ao design de jogos: representação, interação, conflito e segurança. Estes elementos reforçam características necessárias para promover sensações e emoções ao 
usuário a partir de diferentes representações, além de lidar com dificuldades e conflitos em ações controladas por ele durante as interações com o mundo lúdico do jogo. Para Ferreira e Rodrigues (2015), a ludicidade é um atributo que torna a interface atraente, principalmente quando relaciona a diversão aos objetivos de aprendizagem e processos cognitivos adequados. A relação entre a ludicidade e a interface nem sempre é estabelecida em jogos sérios, o que torna questionável a sua qualidade para a aprendizagem. Tradicionalmente, a concepção de um jogo sério sob a perspectiva pedagógica, preocupa-se em relacionar o conteúdo a uma dinâmica que favoreça a aprendizagem. Sobrepor o conteúdo em jogos sérios é tarefa desafiadora porque a dinâmica do "aprender brincando" acontece indiretamente quando há boas representações visuais e conceituais com características adequadas na interface.

Jogos sérios também podem trabalhar habilidades cognitivas, além de conteúdo. Este artigo apresenta o jogo Candy Night focado em funções executivas e reforça como as implicações de design incluídas na sua interface direcionam o usuário aos objetivos de aprendizagem, sem perder a diversão e entretenimento do usuário. Ao considerar este contexto, o artigo reforça a necessidade de relacionar estratégias de design em interfaces de jogos sérios e apresenta decisões do projeto do jogo, ao destacar escolhas para representar a interface em prol dos objetivos de aprendizagem e ludicidade. $\mathrm{O}$ artigo possui cinco seções e está estruturado da seguinte forma: a Seção 2 aponta principais referenciais teóricos, além de discutir sobre interfaces de jogos educativos para o contexto de habilidade cognitivas; a Seção 3 apresenta detalhes da interface do jogo Candy Night e as principais decisões para garantir a diversão e cognição; a Seção 4 apresenta os resultados de uma avaliação da qualidade da interface do jogo Candy Night baseada em critérios como representação (visual e conceitual) e feedback (visual, auditivo e lúdico); e a Seção 5 apresenta as considerações finais.

\section{Principais referenciais teóricos}

Esta seção apresenta definições que contribuem para a promoção da qualidade das interfaces educativas. O termo qualidade é usado neste artigo para destacar o atributo ludicidade, como elemento essencial às interfaces de jogos sérios.

A ludicidade se refere à qualidade do que é lúdico e como termo utilizado na educação infantil, designa atividades, brincadeiras e jogos. Huizinga (2001) pressupõe algumas características para conceituar "jogo" e destaca o ambiente do jogo como um universo lúdico. Para Huizinga (2001), o jogo representa um intervalo da vida cotidiana e não é real. É onde o jogador consegue assumir e realizar coisas diferentes, como ter as habilidades de um bom jogador de futebol, por exemplo, sem nem mesmo saber jogar no mundo real. É um universo paralelo com leis e costumes diferentes, que aguça a imaginação e promove experiências fantasiosas. Neste mesmo sentido, Mastrocola (2012) usa a expressão "círculo mágico" para mencionar que experiências e aprendizados vivenciados no jogo podem influenciar decisões da vida real. Para Mastrocola (2012), o jogo precisa promover eventos especiais, como situações apresentadas de forma diferente, para que o usuário se divirta e se mantenha imerso no universo lúdico. No caso de um jogo de futebol, por exemplo, o jogador poderia usar uma chuteira "especial" com características que diferem do contexto do mundo real. O especial em usar uma "chuteira que brilha", por exemplo, seria promover ao jogador a habilidade de correr, promovendo velocidade durante um determinado tempo. 
Esta pesquisa entende que a ludicidade em jogos sérios pode ser promovida por eventos lúdicos que garantem ao usuário a diversão ao receber um determinado poder, recompensa ou agir diferente da vida real. Conceber eventos especiais, por si só, não garante a diversão em jogos principalmente quando a interface não possui representações visuais com efeitos e funções adequadas. O poder do uso de imagens, animações e outros recursos visuais quando usados corretamente, promovem qualidade na interação. Para Reategui (2007), as ilustrações podem provocar efeitos "como de motivação e elaboração". Imagens com efeito de motivação tendem impulsionar o usuário, no sentido de motivá-lo a realizar ou não uma ação. E o efeito de elaboração acontece quando uma imagem ilustra um conceito, e o usuário consegue associar ao conteúdo lido. As imagens também podem ser empregadas em relação a funções, como a classificação de Mayer (decorativa, representativa, organizacional e explanatória) descritas em Reategui (2007). A função decorativa trata de melhorar a aparência da interface, a representativa ajuda a exemplificar um conceito (representado em texto), a organizacional, ilustra relações entre conceitos e elementos e a explanatória para quando se deseja explicar conceitos mais complexos, sistemas dinâmicos.

Empregar funções e efeitos adequados nas imagens e ilustrações das interfaces em jogos educativos é uma estratégia simples, mas que promove um impacto positivo na interação, consequentemente na aprendizagem. Esta pesquisa observou se as interfaces de jogos educativos focados no desenvolvimento de habilidades cognitivas possuem representações visuais adequadas e se de fato é um jogo lúdico. Uma análise baseada em critérios foi realizada com cinco jogos digitais, três deles da Escola do cérebro: "Genius", "Joaninha" e "Connectome", e os demais "Resta um" e "Colorsok". Todos os jogos são voltados ao aprimoramento de habilidades cognitivas no contexto escolar com referência a funções executivas como memória de trabalho, atenção e resolução de problemas [Ramos e Anastácio, 2018; Ramos, 2015 e Ramos, 2013].

A avaliação foi conduzida pelas autoras seguindo a ordem das atividades: 1) Acessar os jogos para conhecê-los; 2) Jogar, com o propósito de entender a dinâmica; 3) Analisar os jogos sob os parâmetros estabelecidos e 4) Discutir sobre os resultados. Para conduzir a análise, dois parâmetros (representações e feedbacks) foram considerados com o propósito de orientar a observação direta das interfaces: 1) Representações: i) visuais: uso de imagens, animações e/ou ilustrações que contribuem para chamar a atenção do usuário e favorecer a sua percepção, para que ele consiga tomar decisões adequadas no jogo; e ii) conceituais: uso de imagens, animações e/ou ilustrações que contribuem para a memorização e o aprendizado do usuário, considerando o propósito pedagógico do jogo; 2) Feedback: i) visual: para o usuário realizar e concluir ações; ii) auditivo: associado ao uso de estímulos sonoros; iii) lúdico: associado a respostas coerentes ao estímulo divertido do jogo (uso de recursos, poderes, recompensas, e outros, associados a eventos especiais ativados pelo usuário). Uma avaliação baseada em critérios, conforme citado em Silva e Gomes (2015) é uma técnica de avaliação centrada nas interfaces no qual adota critérios de boas práticas de design de interfaces. Geralmente, listas de critérios mais longos e detalhados são adotados. Para Silva e Gomes (2015), os critérios também podem ser elaborados pelos professores, e neste caso, pelas pesquisadoras, partindo do objetivo da avaliação e do que se almeja alcançar com o uso do software. Por se tratar de jogos cognitivos, ou seja, jogos que desenvolvem habilidades cognitivas, não há como e nem intenção de avaliar a perspectiva de conteúdo. O Quadro 1 apresenta informações da avaliação por parâmetro 
para cada jogo em uma escala de: Atende (A); Atende Parcialmente (AP) e Não Atende (NA).

Quadro 1. Resultado da análise dos jogos cognitivos.

\begin{tabular}{|l|c|c|c|c|c|}
\hline \multirow{2}{*}{ Jogos } & \multicolumn{2}{|c|}{ Representação } & \multicolumn{3}{c|}{ Feedback } \\
\cline { 2 - 6 } & Visual & Conceitual & Visual & Auditivo & Lúdico \\
\hline Genius & $\mathrm{A}$ & $\mathrm{A}$ & $\mathrm{A}$ & $\mathrm{NA}$ & NA \\
\hline Joaninha & $\mathrm{A}$ & $\mathrm{A}$ & $\mathrm{A}$ & NA & NA \\
\hline Connectome & $\mathrm{A}$ & $\mathrm{A}$ & $\mathrm{AP}$ & NA & NA \\
\hline Colorsok & $\mathrm{A}$ & $\mathrm{A}$ & $\mathrm{NA}$ & $\mathrm{AP}$ & NA \\
\hline Resta um & $\mathrm{A}$ & $\mathrm{A}$ & $\mathrm{A}$ & $\mathrm{A}$ & $\mathrm{A}$ \\
\hline
\end{tabular}

O Quadro 1 revela que as interfaces de todos os jogos atendem representações visuais e conceituais. A representação conceitual, na avaliação, indica que os jogos realmente trabalham com a estimulação cognitiva. Alinhadas a representações visuais com dinâmicas (apresentadas em animações e imagens), contribuem para o alcance do objetivo. Mesmo que o jogo educativo contribua para a aprendizagem e desenvolvimento de habilidades cognitivas, como é o caso dos avaliados, percebe-se que, sua maioria, não atende ao critério da ludicidade associado ao feedback. A ludicidade é responsável por tornar a experiência de aprendizagem divertida e este resultado revela o quanto que os jogos classificados como educativos/sérios focam apenas nas representações, que nem sempre são de qualidade. Além disso, é importante considerar que a avaliação buscou verificar se atende ou não, sem especificar se as representações visuais são de qualidade (ou seja, refletem efeitos e funções adequadas na interface para o contexto do jogo). Jogos que desconsideram o uso de eventos especiais e um universo lúdico geralmente promovem experiências entediantes para o usuário que espera se divertir ao invés de aprender algo. Jogos focados no desenvolvimento de habilidades cognitivas também devem promover a diversão. Esta relação de diversão e desenvolvimento de habilidades cognitivas é garantida quando um universo lúdico é estabelecido ao contexto do jogo e ao considerar eventos lúdicos, como no jogo apresentado na próxima seção deste artigo.

\section{Ludicidade na interface do jogo}

O jogo Candy Night foi desenvolvido com o intuito de estimular o controle inibitório em crianças, como uma das funções executivas necessárias ao processo de aprendizagem. De acordo com Rodrigues, Torcate e Santos (2019), os objetivos pedagógicos do jogo refletem processos do domínio cognitivo focados em controlar impulsos, planejar ações para executá-las adequadamente. Na perspectiva da Psicologia cognitiva, autores (Léon et al., 2013; Ramos \& Garcia, 2019; Carvalho \& Abreu, 2014) apontam que o controle inibitório é uma função executiva imprescindível para o autocontrole, atuando na inibição comportamentos inadequados e impulsivos.

O processo de concepção pedagógica do jogo considera como lógica básica o "Teste do Marshmallow", que para Mischel (2014), tem como objetivo principal testar em crianças a capacidade de retardar uma satisfação/vontade imediata em prol de benefícios futuros. O teste propõe que crianças possam esperar por um determinado tempo para conseguir comer o doce - "Você pode comer o marshmallow a hora que quiser, mas se conseguir resistir por 15 minutos e não o comer, ganhará dois marshmallows". A intenção do teste é observar/medir quanto tempo cada criança conseguiria resistir e controlar o impulso de não comer o doce. 
Ao considerar este contexto, o jogo Candy Night garante a ludicidade por meio de eventos especiais associados a variável tempo, como no teste do marshmallow. Detalhes sobre os eventos especiais e processos cognitivos do jogo é apresentado em Rodrigues, Torcate e Santos (2019). Esta seção do artigo destaca quais as funções e efeitos adotados aplicados na interface com a intenção de promover a sua qualidade. Todas as imagens e animações incluídas no jogo foram classificadas de acordo com efeito e função, discutidos em Reategui (2007). A Figura 1 destaca elementos da tela do jogo para justificar a função decorativa para agregar elementos decorativos no cenário do jogo.
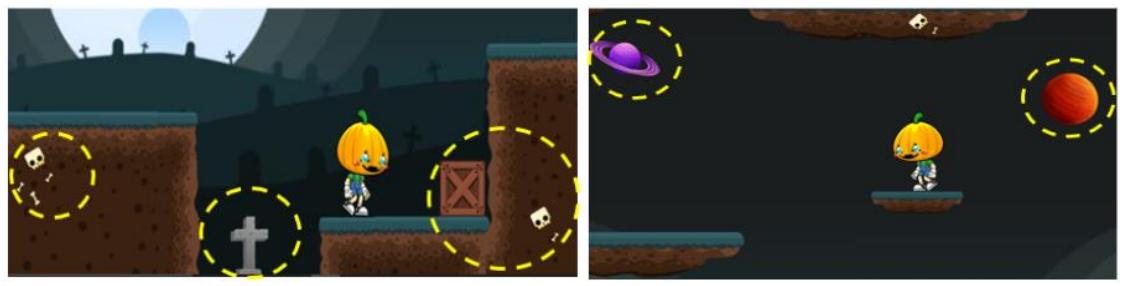

Figura 1. Elementos decorativos do jogo.

Como o contexto do jogo é o Halloween, referências sobre este tema foram consideradas. Imagens dos planetas não carregam nenhuma conotação ligada a aprendizagem. A Figura 2 destaca elementos visuais classificados com a função organizacional. Os elementos destacam eventos especiais de recompensa para que o jogador consiga receber um poder e ganhar vida.
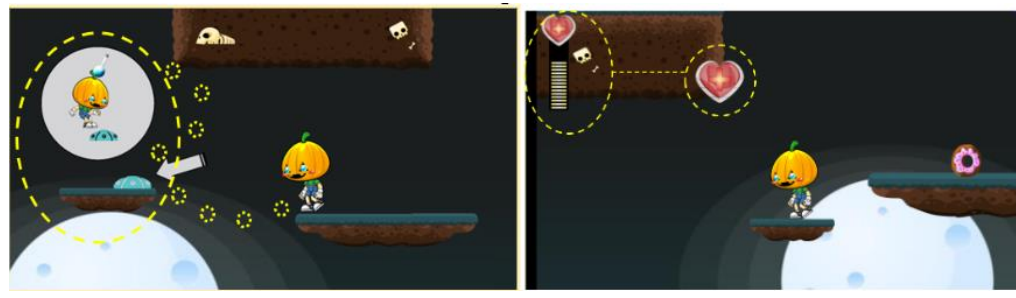

Figura 2. Elementos visuais com função organizacional e efeito motivação.

Sob a perspectiva dos efeitos, os elementos da plataforma azul e o coração possuem efeito de motivação, o que fornece ao usuário o impulso de garantir um recurso. Neste caso, a diversão por esperar 20s sobre a plataforma está associado a possibilidade de garantir a imunidade, impedindo que os inimigos possam atingi-lo. Além deste poder com esta representação, outras plataformas de cores diferentes são usadas para promover diversão após sua espera: i) sorte: representada por um trevo de quatro folhas e o jogador pode escolher dois inimigos para que eles desapareçam; e ii) ação paralisar: representada por um antídoto de cor vermelha usado para paralisar os inimigos por 20s. A dinâmica implementada neste caso "forçava" o usuário a esperar e se houvesse movimentações, a recompensa demorava mais para ser adquirida. A Figura 3 destaca elementos visuais classificados com as funções: exploratória e representativa.
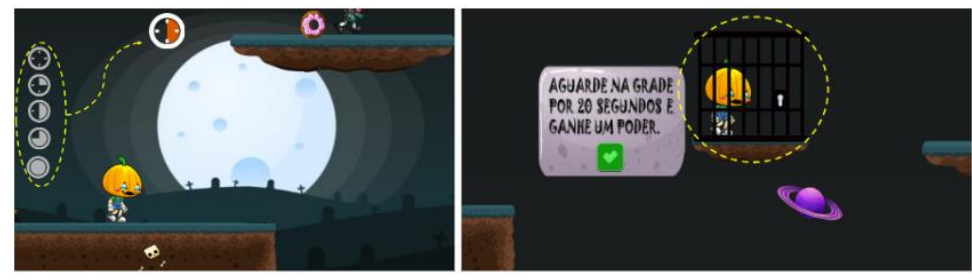


\section{Figura 3. Elementos visuais com função exploratória e representativa.}

A função exploratória revela na interface o funcionamento do relógio, com animação do tempo necessário para o usuário pensar e agir corretamente diante a situação do jogo. Neste caso, o efeito associado ao relógio também garante a motivação em aguardar o tempo para realizar uma ação. A ilustração tem função representativa e efeito de elaboração uma vez que ao ler o texto o jogador representará a imagem da grade e a possibilidade de ganhar uma recompensa. A Figura 4 destaca elementos visuais com efeitos de motivação, associados à abóbora para depósito dos doces e a serra.
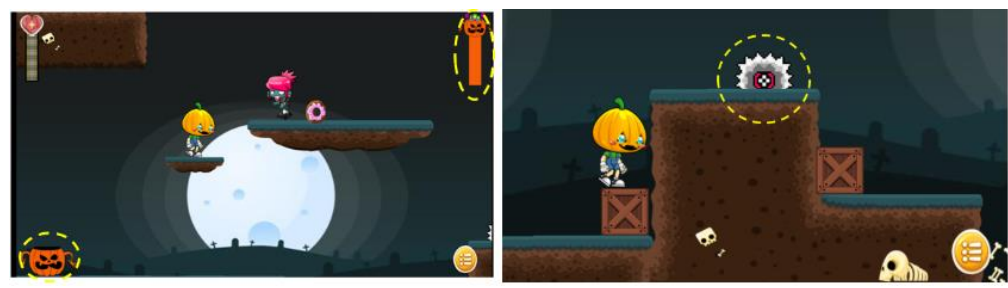

Figura 4. Elementos visuais com efeitos de motivação.

Estas representações impulsionam o jogador a atingir o seu objetivo de coletar os doces e aguardar o bloqueio (como a serra, que aparece e desaparece, assim como para as grades e inimigos). Toda vez que o jogador deposita um doce coletado, um som é emitido e a barra é alimentada, favorecendo a percepção do usuário em relação a quantidade de doces recolhidos e o quanto que falta recolher. As imagens das telas do jogo Candy Night apresentadas nesta seção refletem sobre a aplicação de estratégias visuais para promover a diversão nas interfaces dos jogos agregando efeitos positivos na interação. Esta pesquisa reforça que a interface deve ser bem pensada e projetada, inclusive para atender outras características essenciais ao jogo. O Quadro 2 relaciona detalhes dos elementos citados em Crawford (1982) ao jogo Candy Night, que influenciam diretamente na projeção das interfaces.

Quadro 2. Estratégias lúdicas para atender os elementos de design.

\begin{tabular}{|l|l|}
\hline \multicolumn{1}{|c|}{ Elementos } & \multicolumn{1}{c|}{ Estratégias lúdicas } \\
\hline Representação & $\begin{array}{l}\text { Definição de um universo lúdico, com leis e costumes diferentes do mundo real. Uso } \\
\text { de representações variadas para promover ricas interações. }\end{array}$ \\
\hline Interação & $\begin{array}{l}\text { O usuário tem que sentir que controla o personagem, ele escolhe quais recompensas } \\
\text { deseja obter e quando ativar. Estabeleça regras claras para o usuário. }\end{array}$ \\
\hline Conflito & $\begin{array}{l}\text { Definição de obstáculos que desafiam o usuário e que o comprometem a atingir seu } \\
\text { objetivo. Estabelecer possibilidades para enfrentar os obstáculos, motivando o usuário } \\
\text { a pensar em melhores estratégias. }\end{array}$ \\
\hline Segurança & $\begin{array}{l}\text { Definição de sensação de perigo não real, estabelecendo situações e consequências } \\
\text { para o jogador no jogo. }\end{array}$ \\
\hline
\end{tabular}

O elemento representação, indicado por Crawford (1982), é responsável por combinar recursos que possam enriquecer as sensações de imersão no jogo. Por sua vez, o elemento interação está ligado às regras do jogo, o que estipula as ações do jogador, seus objetivos e possibilidades de melhorar o seu range. No caso do jogo Candy Night, a experiência lúdica proporciona ao jogador o controle das ações do personagem principal, como andar, pular e pegar, associado a recursos que garantem poderes que podem ser ativados quando o usuário desejar. O elemento conflito representa situações no jogo tratadas como obstáculos que o usuário pode se deparar no universo lúdico. Não 
só definir obstáculos é importante como também trazer alternativas para que o usuário possa pensar sobre o que é o mais adequado a se fazer. Por fim, o elemento segurança evidencia a possibilidade de promover sensações de risco com consequências não reais para o usuário. Para este elemento, o jogo Candy Night, usa bloqueios que atrapalham propositalmente o jogador, como é o caso das serras, grades e inimigos espalhados no caminho. As consequências para caso de colisão entre o jogador e estes bloqueios representa a perda de vidas. A próxima seção apresenta resultados da avaliação do jogo Candy Night, destacando aspectos da interface, focada na qualidade das representações e feedback.

\section{Resultados}

Esta seção descreve o processo de aplicação do jogo Candy Night com usuários reais e destaca parte dos resultados da avaliação ao considerar a perspectiva da qualidade da interface. Toda avaliação foi planejada e conduzida conforme o modelo de avaliação composto por cinco etapas (Preparação, Coleta de dados, Consolidação, Interpretação e Resultados), proposto por Barbosa e Silva (2010).

A aplicação do jogo foi realizada com seis alunos, cinco do sexo feminino e um masculino, com faixa etária entre 9 a 12 anos. Os participantes foram selecionados pelo critério da proximidade e manuseio com notebook, uma vez que o jogo foi desenvolvido para executar em desktop. A aplicação durou em média 70 minutos. Nos primeiros 20 minutos, os participantes realizaram uma exploração livre. A intenção foi de proporcionar uma interação inicial onde o participante pudesse se familiarizar com o contexto e dinâmica do jogo antes da avaliação. Os participantes tiveram, em média, 35 min para jogar e 15 minutos para responder um questionário. Durante toda aplicação, o avaliador observou e registrou as experiências dos usuários para possíveis comparações que possam justificar suas respostas.

As afirmações usadas na avaliação consideram os elementos visuais da interface, além da capacidade de promover feedback e como as representações atendem os objetivos educacionais e ludicidade do jogo. Os resultados da avaliação revelam a percepção dos usuários quanto a estes aspectos, definidos conforme a escala "concordo, indeciso e discordo".

A Figura 5 apresenta os gráficos para a percepção dos usuários quanto a representação visual e conceitual.
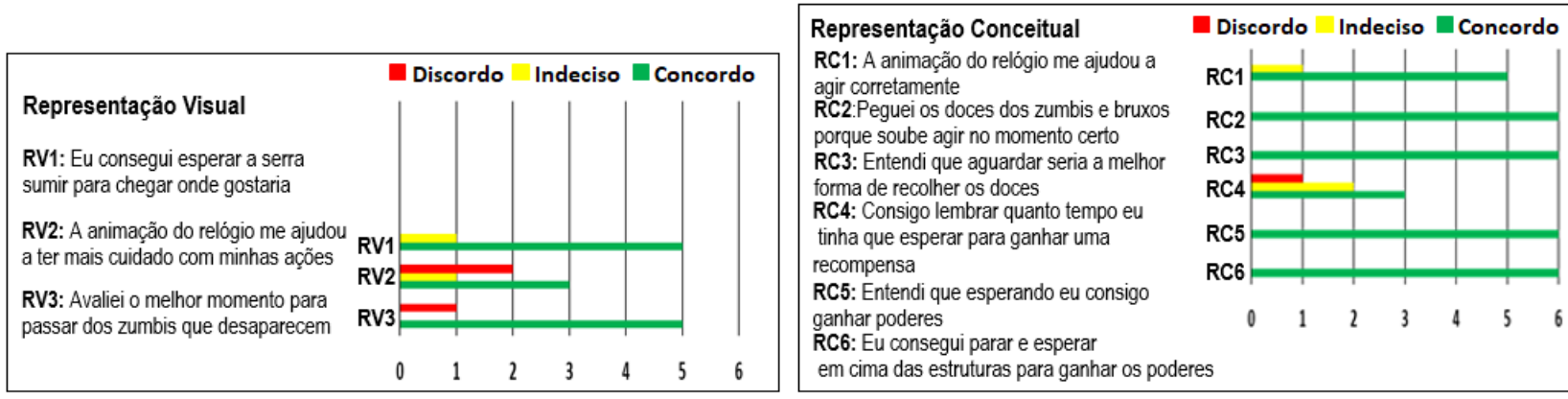

Figura 5. Resultados para a representação visual e conceitual

As afirmações da representação visual estão relacionadas aos elementos visuais do jogo. Elas destacam a serra, a animação do relógio e os zumbis por considerar que 
chamam a atenção e favorecem a percepção do jogador para a tomada de decisão. $O$ resultado da RV1 revela que cinco participantes conseguiram esperar a serra sumir para continuar a coleta dos doces e, um manteve-se indeciso. Para a RV2, durante a interação foi observado que os participantes percebiam o relógio, mas que não se mantinham atentos a animação do tempo. Atribui-se este resultado a possibilidade de o jogador prestar atenção a outros detalhes do jogo, como nos zumbis que se movimentam em todo o cenário. Este resultado permite refletir sobre a necessidade de uma mudança na representação visual ou inclusão estratégica do elemento em um lugar com menos distrações. O resultado para a RV3 indica que houve planejamento das ações em momentos em que os zumbis apareciam no cenário. Estes resultados indicam que os elementos visuais influenciaram positivamente a interação. Por sua vez, os resultados para a representação conceitual foram satisfatórios por atender os objetivos cognitivos do jogo, promovendo o controle e impulsão pelas ações, além do planejamento estratégico. $\mathrm{O}$ uso dos elementos visuais contribuiu para o aprendizado sobre aguardar os eventos e situações no cenário e agir adequadamente. A Figura 6 apresenta os resultados sobre o feedback visual e auditivo.

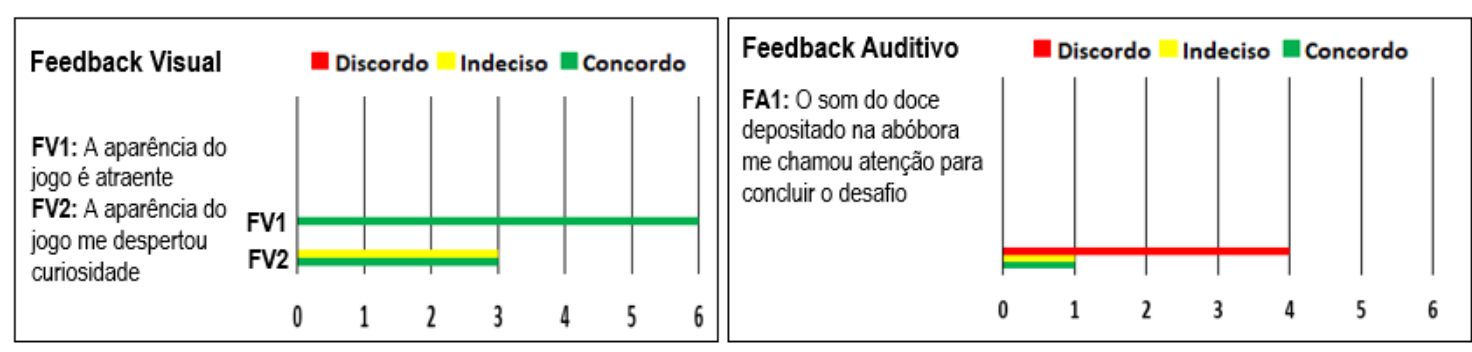

Figura 6. Resultados para o feedback visual e auditivo

O resultado sobre a aparência do jogo revela a satisfação dos participantes quanto ao cenário e seus elementos. Mesmo assim foi observado que alguns participantes tinham dificuldade de direção das setas do teclado usado para movimentar o personagem e isso o impossibilitou ver todo o cenário. Essa justificativa reforça a indecisão sobre "aparência despertar curiosidade", como resultado para a FV2. Por sua vez, o resultado do feedback auditivo foi negativo porque a avaliação foi realizada na biblioteca e como é um ambiente que requer silêncio, o som precisou ser mantido em volume baixo. A Figura 7 apresenta os resultados do feedback lúdico.

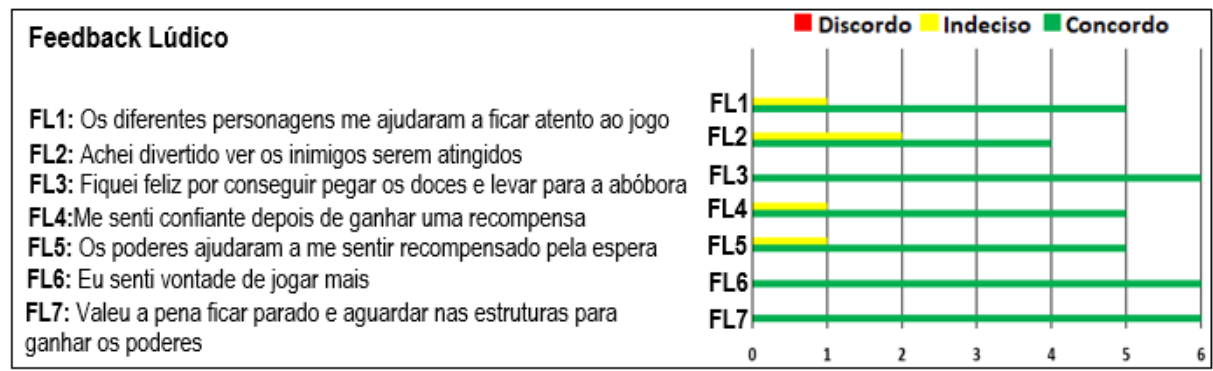

Figura 7. Resultados para o feedback lúdico.

Como apresenta o gráfico, os resultados foram positivos, mesmo com algumas respostas indecisas. De uma maneira geral, pode-se considerar que os aspectos lúdicos do jogo promoveram uma experiência de satisfação, em especial, pelo jogador se sentir recompensado com a espera (FL5 e FL7), atendendo ao objetivo cognitivo do jogo. O uso de poderes como recompensa foi indispensável para promover a diversão do 
jogador, proporcionando a sensação de felicidade por conseguir atingir o objetivo de coleta dos doces (FL3) e confiança, ao combater os inimigos com os poderes adquiridos (FL2). Acredita-se que os eventos especiais, associados como recompensas, contribuíram para a vontade de querer jogar mais (FL6). Estes resultados revelam a importância em garantir experiências divertidas em jogos sérios, representados na interface com feedbacks adequados, para que os objetivos de aprendizagem do jogo possam ser garantidos indiretamente brincando.

\section{Considerações Finais}

Esta pesquisa defende que a qualidade da interface em jogos sérios deve contemplar boas representações, tanto visuais quanto conceituais. Além disso, também considera que feedbacks coerentes às ações do usuário aliados à diversão direcionam o jogador ao alcance do objetivo pedagógico do jogo. O objetivo pedagógico do Candy Night está relacionado a estimulação de habilidades cognitivas para o controle inibitório e promove situações para que o jogador possa controlar impulsos como parar, esperar e pensar em qual decisão deve tomar. A parte divertida deste processo é considerada nas situações em que o jogador consegue adquirir e ativar poderes que o ajudam no combate dos inimigos durante a coleta dos doces. As recompensas trazem motivação para o jogador se manter no jogo e consequentemente favorecer a estimulação das habilidades.

$\mathrm{O}$ que queremos reforçar com esta pesquisa é que definir um universo lúdico com eventos especiais não é uma garantia para a eficácia do jogo, pedagogicamente falando. Isso reforça que a concepção de um jogo sério deve manter o equilíbrio entre "ser divertido" com a "aprendizagem" para então atingir o seu objetivo pedagógico principal. Ou seja, a diversão não deve se sobrepor aos objetivos educacionais para qual o jogo se destina. Neste caso, a aplicação de teorias para representar adequadamente a interface é uma atividade que merece ser mais discutida em projetos de desenvolvimento de jogos.

Os próximos passos da pesquisa envolvem o planejamento e execução de avaliações das interfaces do Candy Night com métodos de observação em uso. Além disso, produzir um cenário de aprendizagem para guiar sua aplicação no contexto escolar.

\section{Referências}

Barbosa, S. D. J.; Silva, B. S. (2010). "Interação Humano - Computador". Editora Campus - Elsevier.

Carvalho, C. e Abreu, N. (2014). "Estimulando Funções Executivas em sala de aula: O programa heróis da mente". I Seminário Tecnologias Aplicadas a Educação e Saúde. UNEB, Campus I, Salvador-BA.

Crawford, C. (1982). "The Art of Computer Game Design". Washington State University Vancouver (WSUV). Disponível em: < https://book.huihoo.com/the-artof-computer-game-design/> Acessado em 08 de junho de 2020.

Ferreira, M. A. D.; Rodrigues, A. N. (2015). "Interfaces Educativas: Implicações de design e processos cognitivos do jogo Nicetown". Anais do XXVI Simpósio Brasileiro de Informática na Educação (SBIE 2015).

Huizinga, J. (2001). "Homo ludens”. São Paulo: Perspectiva. 
León, C. B. R.; Rodrigues, C. C.; Seabra, A. G.; Dias, N. M. (2013). "Funções executivas e desempenho escolar em crianças de 6 a 9 anos de idade". Rev. Psicopedagogia; 30(92): 113-20.

Mastrocola, V. M. (2012). "Ludificador: um guia de referências para o game designer brasileiro". São Paulo: Independente.

Mischel, W. (2014). “The Marshmallow Test: Mastering Self-Control”. Editora: Little Brown and Company. ISBN-10: 0316230871.

Ramos, D. K. e Anastácio, B. S. (2018). "Habilidades cognitivas e o uso de jogos digitais na escola: A percepção das crianças". Revista: Educação Unisinos. Editora: Universidade do Vale do Rio dos Sinos.

Ramos, D. K. (2015). "O uso da Escola do Cérebro no Ensino Fundamental: contribuições ao aprimoramento das habilidades cognitivas". Seminário de Tecnologias aplicadas a Educação e Saúde (II STAES).

Ramos, D. K. e Garcia, F. A. (2019). "Jogos digitais e aprimoramento do controle inibitório: um estudo com crianças do atendimento educacional especializado". Rev. Bras. Ed. Esp., Bauru, v.25, n.1, p.37-54.

Ramos, D. K. (2013). "Jogos cognitivos eletrônicos na escola: exercício e aprimoramento dos aspectos cognitivos". IX Seminário de Jogos Eletrônicos, Educação e Comunicação.

Reategui, E. (2007). "Interfaces para Softwares Educativos”. Revista Novas Tecnologias na Educação (RENOTE).

Rodrigues, A. N. Torcate, A. S. Santos, C. C. (2019). "A relação entre a ludicidade e a cognição em um jogo para o controle inibitório". IV Congresso sobre Tecnologias na Educação (Ctrl+e 2019).

Silva, A. C. B da; Gomes, A. S. (2015). "Conheça e utilize software educativo: avaliação e planejamento para a educação básica”. Série Professor Criativo - Vol. 2. 